\title{
Risk factors for progression of solitary plasmacytoma of bone to multiple myeloma in the spine: A population-based study
}

\section{Lin Xie}

Huashan Hospital Fudan University

Hongli Wang

Huashan Hospital Fudan University

Jianyuan Jiang ( $\sim 18111220066 @ f u d a n . e d u . c n)$

Huashan Hospital Fudan University

Chaojun Zheng

Huashan Hospital Fudan University

Research article

Keywords: Solitary plasmacytoma of bone, Multiple myeloma (MM), Risk factor, Progression

Posted Date: February 24th, 2020

DOI: https://doi.org/10.21203/rs.2.17500/v2

License: (c) (i) This work is licensed under a Creative Commons Attribution 4.0 International License.

Read Full License 


\section{Abstract}

Background: Spine SBP is a primary spinal malignant tumor. Risk factors associated with progression of solitary plasmacytoma of bone (SBP) to multiple myeloma in spine remains unknown. This study therefore aimed to identify the risk factors associated with progression of solitary plasmacytoma of bone (SBP) to multiple myeloma in the spine.

Methods: Data of 1543 patients diagnosed with spine SBP between 1992 and 2013 was obtained from the Surveillance, Epidemiology, and End Results (SEER) database for analysis. Risk factors associated with progression of SBP to multiple myeloma (MM) were then identified using univariate and multivariate regression analysis methods.

Results: Out of the 1543 patients diagnosed with spine SBP, 659 of them progressed to MM. The overall rate of progression to MM was $42.51 \%$. Univariate and multivariate regression analysis revealed that age, race, gender and chemotherapy were independent risk factors associated with SBP progression to MM.

Conclusion: Old aged patients, patients belonging to the white race, female patients and those undergoing chemotherapy were identified to be at a high risk of progression to $\mathrm{MM}$. This information will assist clinicians in evaluating patients' risk of SBP progression to MM at the point of diagnosis and advise them accordingly.

\section{Background}

Plasmacytomas are malignant tumors characterized by clonal proliferations of plasma cells. They can be classified into three groups: multiple myeloma (MM), extramedullary plasmacytoma (EMP) and solitary plasmacytoma of bone (SBP) [1]. SBP's account for approximately $5 \%$ of plasmacytomas. The ratio of male to female patients diagnosed with SBP is 2:1 [2, 3]. Spine SBP is a mass of neoplastic monoclonal plasma cells in spinal bones. Nearly $70 \%$ of SBP's primarily occur in the spine commonly in the thoracic vertebrae of red marrow-containing bones [4-6].

Previous study reported that patients diagnosed with SBP have high risk of progression to MM [7]. 50 $60 \%$ of patients diagnosed with SBP develop to MM [7]. Knobel et al., reported that the median time of SBP development to MM was 21 months. $51 \%$ of patients had probability of SBP developing to MM within 5 years [8]. In the same line, Bertanha et al., reported the average time of SBP development to MM was 41 months. SBP in the spine have a high likelihood to progress to MM than SBP in other bone sites. For instance, Yang et al., reported a case of rapid progression of solitary plasmacytoma to MM in lumbar vertebra. To the best of the authors' knowledge, information regarding risk factors associated with progression of SBP in the spine is still lacking.

As such, the Surveillance, Epidemiology, and End Results (SEER) database was used to enroll enough spine SBP patients for the study. This was done because obtaining enough patients diagnosed with spine 
SBP for the study was a big challenge. The SEER database has been widely used as an effective tool for analysis of rare cancers [11-13].

This study aimed to identify factors associated with increased risk of progression of spine SBP to MM. The study is expected to provide more information that will assist clinicians in evaluating patients' risk of SBP progression to MM at the point of diagnosis.

\section{Methods}

\section{Patients cohort}

A population-based search for patients diagnosed with primary spinal bone tumor was performed in the National Cancer Institute's SEER database (with additional treatments) [http://seer.cancer.gov]. The database contained numerous cancer data derived from 18 cancer registries across the United States. The cancer registries covered approximately $30 \%$ of the US population. The SEER database had widely been used and validated independently for analysis of primary spinal bone tumor. The study did not require approval from the internal review board because the SEER database uses publicly available information with no personal identifiers. ICD-0-3 codes were reviewed for all patients to identify the histological subtypes of "solitary bone plasmacytoma (9731/3)". Site-specific codes were first used to identify all primary spinal bone tumors. The codes were; C41.2 for the vertebral column and C41.4 for pelvic bones, sacrum, coccyx and associated joints. Data on SP-bone staging (extension of disease (EOD)) was limited to only two main categories; "local" and "distant". However, patients with "distant" involvement were not of interest because spine SBP is a localized single mass of monoclonal plasma cells in the spine. Cognizant to this, patients designated as "distant" were excluded from the study. Patients diagnosed with second or later primary cancer, those diagnosed using a death certificate or autopsy results, those with unknown survival time and those of unspecified race were also excluded. Patients whose spine SBP progressed to MM were also identified (Figure 1).

\section{Statistical analysis}

The incorporated variables of the group of patients whose spine SBP progressed to MM and that of those whose spine SBP didn't progress to MM were compared using the chi-squared test. Univariate logistic regression analysis of the age, year of diagnosis, gender, race, marital status, grade, radiotherapy sequence, surgery, radiotherapy and chemotherapy of the patients was used to identify possible risk factors associated with SBP progression to MM. Multivariate logistic analysis was then applied to further evaluate the risk factors identified in the univariate logistic regression analysis. Statistical analyses were performed using SEER ${ }^{\star S}$ tat version 8.3.4 (NCl., Bethesda., MD), SPSS version 23 (IBM Corp., Armonk, New York, USA) and R version 3.3.1 (Institute for Statistics and Mathematics, Vienna, Austria) software. Differences between groups were deemed to be statistically significant when the $p$ value was less than $0.05(p<0.05)$. 


\section{Results}

\section{Patients baseline characteristics}

8195 patients diagnosed with spinal bone tumor between 1983 and 2015 were retrieved from the SEER database. 2147 patients diagnosed as SBP were then selected for another round of screening. Among these patients, 604 were categorized as "distant" or were of unknown race and hence were excluded. The remaining 1543 patients diagnosed with spine SBP were then included in the study. We identified Patients whose SBP progressed to MM were identified using their cause of death (COD) and their ID's being found in both SBP and MM patients' databases. Finally, 659 patients whose spine SBP progressed to MM were identified (Figure 1).

Patients characteristics are listed in Table 1. 966 (62.6\%) patients were aged above 59 years. Their median age at the point of diagnosis was 63.9 years. 1206 (78.16\%) patients were diagnosed between 2003 and 2015. Histologically, 580 (37.59\%) patients were of pre-B cell grade while 921 (59.69\%) were of unknown grade. Based on gender, 968 (62.73\%) patients were males while the rest $575(37.27 \%)$ were females. Moreover, 989 (64.1\%) patients were married. 1236 (80.1\%) patients were white. Upon diagnosis, 476 (30.85\%) patients underwent surgery, 1275 (82.63\%) patients underwent radiotherapy while $320(20.74 \%)$ patients underwent radiotherapy after surgery. Nonetheless, $336(21.78 \%)$ patients underwent chemotherapy.

\section{Risk factors associated with SBP progression to MM}

Univariate logistic regression analysis revealed that age, race, gender and chemotherapy were all significantly associated with SBP progression to MM $(p<0.05)$ (Table 2$)$. After controlling for confounding variables using multivariate logistic analysis, age, gender, race and chemotherapy was identified as independent risk factors for SBP progression to MM $(p<0.05)$ (Table 2).

Multivariate logistic analysis revealed an increased risk of SBP progression to MM among patients aged $45-59$ years old $(\mathrm{OR}=1.953,95 \%$ confidence interval $[\mathrm{Cl}]$ of 1.254 to 3.044$), 60-74$ years old $(\mathrm{OR}=2.787$, $95 \% \mathrm{Cl}$ of 1.812 to 4.287$), 75-89$ years old $(\mathrm{OR}=2.877,95 \% \mathrm{Cl}$ of 1.825 to 4.536$)$ and those above 90 years $(\mathrm{OR}=4.350,95 \% \mathrm{Cl}$ of 1.590 to 11.901$)$. Patients belonging to the white race $(\mathrm{OR}=2.032,95 \% \mathrm{Cl}$ of 1.079 to 3.826 ), female patients ( $\mathrm{OR}=1.272,95 \% \mathrm{Cl}$ of 1.027 to 1.576 ) and patients who had undergone chemotherapy (OR $=1.593,95 \% \mathrm{Cl}, 1.243$ to 2.042$)$ also had an increased risk of SBP progression to MM.

\section{Discussion}

In this study, univariate and multivariate logistic analysis revealed that old age, belonging to the white race, being female and undergoing chemotherapy were risk factors that increased the likelihood of SBP progression to MM. All factors were independent of each other. These findings were consistent with those of who reported that old age was an independent risk factor for worse prognosis of SBP patients [17-19]. Similarly, Knobel et al., reported that younger patients with tumors located in the vertebral column had a 
better outcome when treated with moderate-dose radiotherapy [8]. El-Fattah et al., analyzed the risk factors of plasmacytoma mortality using a large population-based study. They found that the age of the patient, black-American race and bone plasmacytomas were significant risk factors associated with low overall survival of patients diagnosed with plasmacytoma [20]. In the same line, Kilciksiz et al., reported that young age was an independent good prognostic factor for progression of SBP to MM [19]. This study revealed that there is a close association between old age and increased likelihood of SBP progressing to MM. These findings partially explained the poor prognosis of plasmacytoma in older patients. However, Bertanha et al., found that patients who progressed to MM were younger than those who did not. In their study, the average time of progression to MM was 41 months [9]. However, the evidence of the risk factor analysis was low because the small sample size of the two groups was only compared using the t test analysis. In our multivariate analysis, SBP patients belonging to the white race had a higher risk of its progression to MM. This was attributed to the high incidence of SBP among the white race individuals. In addition, the rate of SBP progression to MM in female patients was slightly higher than that in male patients. This suggested that progression of SBP to MM could be partially gender dependent. In the same line, SBP patients under chemotherapy regimens were also at a higher risk of progression to MM.

The mean age of patients diagnosed with spine SBP was 63.6 years. The ratio of male to female patients diagnosed with SBP was 1.68:1 indicating that spine SBP often occurred in older men. This was a largescale population retrospective study that was limited to positive SBP diagnosis done between 1992-2013. This was done to reduce diagnosis errors and ensure that the follow-up time after diagnosis was more than 5 years.

\section{Limitations}

Despite the insightful data obtained in this study, it had some limitations. Some risk factors such as tumor size, persistent myeloma and serum free light chain ratio were not available in the SEER database [21]. In addition, there was no data on surgical approaches and time of surgery are available in the database although there were reports of surgical procedures performed. Moreover, the SEER database lacked data on the range and dose of radiation therapy and other treatment methods such as immunotherapy and hormone therapy. Despite these shortcomings, the study generated invaluable information regarding the risk factors associated with SBP's progression to MM.

\section{Conclusions}

Evidently, this study is the largest analysis done to evaluate the progression of spine SBP patients to MM. represents the largest series with risk factors for progression to MM on patients with SBP in spine. Old aged patients, patients belonging to the white race, female patients and those undergoing chemotherapy were identified to be at a high risk of progression to MM. Indeed, this information will assist clinicians in evaluating patients' risk of SBP progression to MM at the point of diagnosis and advise them accordingly. 


\section{Abbreviations}

SBP: solitary plasmacytoma of bone; SEER: Surveillance, Epidemiology, and End Results; MM: multiple myeloma; EMP: extra-medullary plasmacytoma; HRs: hazard ratios; Cls: confidence intervals

\section{Declarations}

\section{Acknowledgments}

None.

\section{Availability of data and materials}

Limited Use Agreement for Surveillance, Epidemiology, and End Results (SEER) Program (https://seer.cancer.gov) SEER ${ }^{\star S}$ tat Database. The data can be used publicly.

\section{Ethics approval and consent to participate}

Anonymized cancer registry data were analyzed in this study, therefore not requiring ethics approval. No patient identifying information is reported.

\section{Consent for publication}

Not Applicable.

\section{Availability of data and materials}

Please contact corresponding author Jianyuan Jiang for data requests.

\section{Competing interests}

The authors declare that they have no competing interests.

\section{Funding}


This work was supported by grants from the National Natural Science Foundation of China (No. 81802145, 81772388, 81972109).

\section{Authors' contributions}

LX and JYJ conceived the study idea. LX, JYJ and HLW performed data mining, and statistical analyses. JYJ and CJZ interpreted results of statistical analyses. LX drafted the initial manuscript. LX and JYJ made critical comment and revision for the initial manuscript. LX had primary responsibility for the final content. LX and HLW are co-first authors. JYJ is correspondence author. All authors reviewed and approved the final manuscript.

\section{Author details}

${ }^{1}$ Department of Orthopedics, Huashan Hospital, Fudan University, 12 Mid-Wulumuqi Road, Shanghai 200040, China.

\section{References}

1. Dores GM, Landgren O, McGlynn KA, Curtis RE, Linet MS, Devesa SS. Plasmacytoma of bone, extramedullary plasmacytoma, and multiple myeloma: incidence and survival in the United States, 1992-2004. Br J Haematol. 2009;144(1):86-94.

2. Caers J, Paiva B, Zamagni E, Leleu X, Blade J, Kristinsson SY, Touzeau C, Abildgaard N, Terpos E, Heusschen R, Ocio E, Delforge M, Sezer O, Beksac M, Ludwig H, Merlini G, Moreau P, Zweegman S, Engelhardt M, Rosinol L. Diagnosis, treatment, and response assessment in solitary plasmacytoma: updated recommendations from a European Expert Panel. J Hematol Oncol. 2018;11(1):10.

3. Thumallapally N, Meshref A, Mousa M, Terjanian T. Solitary plasmacytoma: population-based analysis of survival trends and effect of various treatment modalities in the USA. BMC Cancer. 2017;17(1):13.

4. Weberpals J, Pulte D, Jansen L, Luttmann S, Holleczek B, Nennecke A, Ressing M, Katalinic A, Merz M, Brenner H, Grp GCSW. Survival of patients with lymphoplasmacytic lymphoma and solitary plasmacytoma in Germany and the United States of America in the early 21 st century. Haematologica. 2017;102(6):E229-E232.

5. Tutar S, Mutlu A, Ozturk E, Ulusoy OL, Enercan M. Solitary plasmacytoma of the thoracic spine. Spine J. 2016;16(8):e485.

6. Ma L, Ling T, Li T, Song Y. Slowly progressive solitary plasmacytoma of the thoracic spine. Spine J. 2016;16(2):e21-22. 
7. Albano D, Bosio G, Treglia G, Giubbini R, Bertagna F. 18F-FDG PET/CT in solitary plasmacytoma: metabolic behavior and progression to multiple myeloma. Eur $\mathrm{J}$ Nucl Med Mol Imaging. 2018;45(1):77-84.

8. Knobel D, Zouhair A, Tsang RW, Poortmans P, Belkacemi Y, Bolla M, Oner FD, Landmann C, Castelain $B$, Ozsahin M, Rare Cancer N. Prognostic factors in solitary plasmacytoma of the bone: a multicenter Rare Cancer Network study. BMC Cancer. 2006;5(6):118.

9. Bertanha F, Boufelli G, de Camargo OP, Baptista AM, Caiero MT, de Oliveira CR, Filippi R. Oncologic progression of bone plasmacytomas to multiple myeloma. Clinics (Sao Paulo). 2006;61(2):139-146.

10. Yang JS, Cho YJ, Kang SH, Choi HJ. Rapid progression of solitary plasmacytoma to multiple myeloma in lumbar vertebra. J Korean Neurosurg Soc. 2013;54(5):426-430.

11. Song K, Song J, Shi X, Wang H, Ma X, Xia X, Liang X, Lin K, Jiang J. Development and Validation of Nomograms Predicting Overall and Cancer-Specific Survival of Spinal Chondrosarcoma Patients. Spine. 2018;43(21):E1281-E1289.

12. Song K, Shi X, Wang H, Zou F, Lu F, Ma X, Xia X, Jiang J. Can a Nomogram Help to Predict the Overall and Cancer-specific Survival of Patients With Chondrosarcoma? Clin Orthop Relat Res. 2018;476(5):987-996.

13. Song K, Shi X, Liang X, Wang H, Zou F, Lu F, Ma X, Jiang J. Risk factors for metastasis at presentation with conventional chondrosarcoma: a population-based study. Int Orthop. 2018;42(12):2941-2948.

14. Finsinger P, Grammatico S, Chisini M, Piciocchi A, Foa R, Petrucci MT. Clinical features and prognostic factors in solitary plasmacytoma. Br J Haematol. 2016;172(2):554-560.

15. de Waal EG, Leene M, Veeger N, Vos HJ, Ong F, Smit WG, Hovenga S, Hoogendoorn M, Hogenes M, Beijert M, Diepstra A, Vellenga E. Progression of a solitary plasmacytoma to multiple myeloma. A population-based registry of the northern Netherlands. Br J Haematol. 2016;175(4):661-667.

16. Li Q-W, Niu S-Q, Wang H-Y, Wen G, Li Y-Y, Xia Y-F, Zhang Y-J. Radiotherapy Alone is Associated with Improved Outcomes Over Surgery in the Management of Solitary Plasmacytoma. Asian Pacific Journal of Cancer Prevention. 2015;16(9):3741-3745.

17. Suh YG, Suh CO, Kim JS, Kim SJ, Pyun HO, Cho J. Radiotherapy for solitary plasmacytoma of bone and soft tissue: outcomes and prognostic factors. Ann Hematol. 2012;91(11):1785-1793.

18. Warsame R, Gertz MA, Lacy MQ, Kyle RA, Buadi F, Dingli D, Greipp PR, Hayman SR, Kumar SK, Lust JA, Russell SJ, Witzig TE, Mikhael J, Leung N, Zeldenrust SR, Rajkumar SV, Dispenzieri A. Trends and outcomes of modern staging of solitary plasmacytoma of bone. American Journal of Hematology. 2012;87(7):647-651.

19. Kilciksiz S, Karakoyun-Celik O, Agaoglu FY, Haydaroglu A. A review for solitary plasmacytoma of bone and extramedullary plasmacytoma. ScientificWorldJournal 2012;2012:895765.

20. El-Fattah MA, Aboelmagd M, Elhamouly M. Clinical risk factors of Plasmacytoma mortality: a US population-based study. Br J Haematol. 2017;179(1):161-162. 
21. Hill QA, Rawstron AC, de Tute RM, Owen RG. Outcome prediction in plasmacytoma of bone: a risk model utilizing bone marrow flow cytometry and light-chain analysis. Blood. 2014;124(8):1296-1299.

\section{Tables}

Table. 1 Characteristics of patients with solitary plasmacytoma of bone (SBP) in spine by progression to multiple myeloma (MM).

\begin{tabular}{|c|c|c|c|c|}
\hline Characteristic & $\mathrm{N}(\%)$ & Progression to MM & No progression to MM & $P$ \\
\hline Year & & & & 0.450 \\
\hline 1992-2002 & $337(21.84)$ & 150 & 187 & \\
\hline 2003-2013 & 1206(78.16) & 509 & 697 & \\
\hline Age & & & & $0.000^{*}$ \\
\hline$<45$ & $138(8.94)$ & 32 & 106 & \\
\hline $45-59$ & $439(28.45)$ & 168 & 271 & \\
\hline $60-74$ & 606(39.27) & 284 & 322 & \\
\hline $75-89$ & $341(22.10)$ & 164 & 177 & \\
\hline$>89$ & $19(1.23)$ & 11 & 8 & \\
\hline Race & & & & $0.038^{*}$ \\
\hline White & $1236(80.10)$ & 546 & 690 & \\
\hline Black & $246(15.94)$ & 96 & 149 & \\
\hline Asian or Pacific Islander & $53(3.43)$ & 14 & 39 & \\
\hline American Indian/Alaska Native & $9(0.58)$ & 3 & 6 & \\
\hline Gender & & & & $0.009 *$ \\
\hline Female & $575(37.27)$ & 270 & 305 & \\
\hline Male & $968(62.73)$ & 389 & 579 & \\
\hline Marital status & & & & 0.706 \\
\hline Married & $989(64.10)$ & 433 & 556 & \\
\hline Divorced & $127(8.23)$ & 51 & 76 & \\
\hline Single & 184(11.92) & 74 & 110 & \\
\hline Others & $243(15.75)$ & 101 & 142 & \\
\hline Grade & & & & 0.292 \\
\hline Pre-B cell & $580(37.59)$ & 238 & 342 & \\
\hline Grade 1 & $14(0.91)$ & 6 & 8 & \\
\hline Grade 2 & $8(0.52)$ & 6 & 2 & \\
\hline Grade 3 & $10(0.65)$ & 6 & 4 & \\
\hline Grade 4 & $10(0.65)$ & 3 & 7 & \\
\hline Unknown & 921(59.69) & 400 & 521 & \\
\hline Radiotherapy sequence & & & & 0.990 \\
\hline Before surgery & $32(2.07)$ & 14 & 18 & \\
\hline After surgery & $320(20.74)$ & 136 & 184 & \\
\hline Other or unknown & 1191(77.19) & 509 & 682 & \\
\hline Surgery & & & & 0.890 \\
\hline Yes & $476(30.85)$ & 185 & 251 & \\
\hline No & 1107(71.74) & 474 & 633 & \\
\hline Radiotherapy & & & & 0.152 \\
\hline Yes & 1275(82.63) & 534 & 741 & \\
\hline No or unknown & 268(17.37) & 125 & 143 & \\
\hline Chemotherapy & & & & $0.000 *$ \\
\hline Yes & $336(21.78)$ & 172 & 164 & \\
\hline No or unknown & $1207(78.22)$ & 487 & 720 & \\
\hline
\end{tabular}


Table. 2 Univariate and multivariate logistic regression analysis for patients with solitary plasmacytoma of bone (SBP) in spine by progression to multiple myeloma (MM).

\begin{tabular}{|c|c|c|c|c|}
\hline \multirow[t]{2}{*}{ Characteristic } & \multicolumn{2}{|l|}{ Univariate analysis } & \multicolumn{2}{|l|}{ Multivariate analysis } \\
\hline & OR $(95 \% \mathrm{CI})$ & $P$ & OR $(95 \% \mathrm{CI})$ & $P$ \\
\hline Year & & & $\mathrm{NI}$ & \\
\hline 1992-2002 & Reference & & & \\
\hline 2003-2013 & $0.910(0.714-1.161)$ & 0.450 & & \\
\hline \multicolumn{5}{|l|}{ Age } \\
\hline$<45$ & Reference & & Reference & \\
\hline $45-59$ & $2.054(1.323-3.188)$ & $0.001 *$ & $1.953(1.254-3.044)$ & $0.003^{*}$ \\
\hline $60-74$ & $2.922(1.908-4.475)$ & $0.000 *$ & $2.787(1.812-4.287)$ & $0.000^{*}$ \\
\hline $75-89$ & 3.069 (1.959-4.808) & $0.000 *$ & $2.877(1.825-4.536)$ & $0.000^{*}$ \\
\hline$>89$ & $4.555(1.688-12.292)$ & $0.003 *$ & $4.350(1.590-11.901)$ & $0.004^{*}$ \\
\hline \multicolumn{5}{|l|}{ Race } \\
\hline White & Reference & & $2.032(1.079-3.826)$ & $0.028 *$ \\
\hline Black & $0.814(0.615-1.077)$ & 0.150 & $1.660(0.845-3.259)$ & 0.141 \\
\hline Asian or Pacific Islander & $0.454(0.244-0.844)$ & $0.013^{*}$ & Reference & \\
\hline American Indian/Alaska Native & $0.632(0.157-2.538)$ & 0.518 & $1.147(0.250-5.270)$ & 0.860 \\
\hline \multicolumn{5}{|l|}{ Gender } \\
\hline Female & Reference & & $1.272(1.027-1.576)$ & $0.027^{*}$ \\
\hline Male & 0.759 (0.616-0.935) & $0.009 *$ & Reference & \\
\hline Marital status & & & NI & \\
\hline Married & Reference & & & \\
\hline Divorced & $0.862(0.591-1.255)$ & 0.438 & & \\
\hline Single & $0.864(0.627-1.190)$ & 0.370 & & \\
\hline Others & $0.913(0.687-1.214)$ & 0.532 & & \\
\hline Grade & & & $\mathrm{NI}$ & \\
\hline Pre-B cell & Reference & & & \\
\hline Grade 1 & $1.078(0.369-3.146)$ & 0.891 & & \\
\hline Grade 2 & $4.311(0.863-21.542)$ & 0.075 & & \\
\hline Grade 3 & $2.155(0.602-7.721)$ & 0.238 & & \\
\hline Grade 4 & $0.616(0.158-2.406)$ & 0.486 & & \\
\hline Unknown & 1.103 (0.894-1.362) & 0.360 & & \\
\hline Radiotherapy sequence & & & $\mathrm{NI}$ & \\
\hline Before surgery & Reference & & & \\
\hline After surgery & $0.950(0.457-1.977)$ & 0.892 & & \\
\hline Other or unknown & $0.960(0.473-1.947)$ & 0.909 & & \\
\hline Surgery & & & NI & \\
\hline Yes & Reference & & & \\
\hline No & $1.016(0.812-1.271)$ & 0.890 & & \\
\hline Radiotherapy & & & NI & \\
\hline Yes & Reference & & & \\
\hline No or unknown & $1.213(0.931-1.580)$ & 0.153 & & \\
\hline \multicolumn{5}{|l|}{ Chemotherapy } \\
\hline Yes & Reference & & $1.593(1.243-2.042)$ & $0.001 *$ \\
\hline No or unknown & 0.645 (0.506-0.822) & $0.000 *$ & Reference & \\
\hline
\end{tabular}


Figures

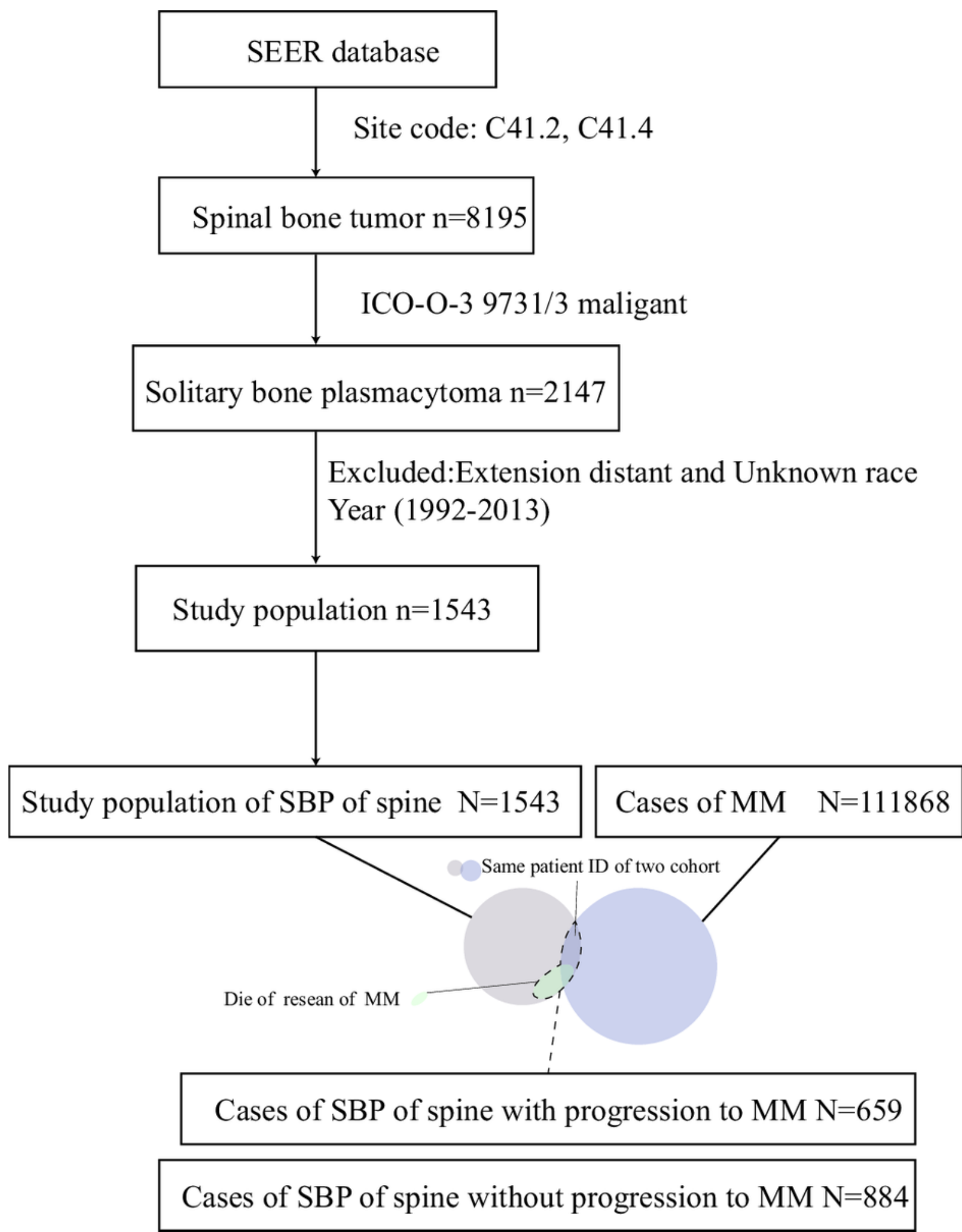

Figure 1

The flow diagram demonstrates the process of selecting patients from the SEER database. 